\title{
Reproduzir ou construir conhecimento? \\ Funções da escrita no contexto escolar português*
}

\author{
JOSÉ ANTÓNIO BRANDÃO CARVALHO \\ Universidade do Minho \\ LUÍS FILIPE BARBEIRO \\ Instituto Politécnico de Leiria
}

\section{INTRODUÇÃO}

Quando se problematiza a escrita no quadro da instituição escolar, duas vertentes podem ser imediatamente identificadas. A primeira perspetiva a escrita como conteúdo escolar a adquirir e desenvolver, sobretudo no espaço reservado à língua materna. É na escola que o indivíduo adquire e desenvolve as competências do domínio do escrito, quer no plano da receção, quer no da expressão. Ao contrário do que acontece com a linguagem oral, cuja aquisição e desenvolvimento se processa pela interação habitual da criança com o meio em que está inserida, sem

* Neste texto, apresentamos estudo que constituiu uma das tarefas de projeto intitulado Escrita Construção e Expressão de Conhecimento (POCI/CED/60155/2004), financiado pela Fundação para a Ciência e a Tecnologia (FCT) portuguesa. Este estudo, desenvolvido no Centro de Investigação em Educação (CIEd) da Universidade do Minho (sob coordenação de José António Brandão Carvalho) e no Instituto Politécnico de Leiria (sob coordenação de Luís Barbeiro), contou com a colaboração dos investigadores João Paulo Ramos e Sílvia Rios, na parte referente à análise de manuais de $3^{\circ}$ ciclo, e de Jorge Pimenta e António Silva, no que diz respeito ao inquérito realizado. 
necessidade de um ensino explícito da competência linguística, cabe à escola, em geral, e à disciplina de língua materna, em particular, dotar aqueles que a frequentam da capacidade de ler e escrever. Nesta linha, a escrita assume-se, portanto, como saber escolarizável e o modo como se lê e se escreve, na escola e para além dela, enquanto a frequentamos ou depois de dela sairmos, funciona como um indicador da eficácia da própria escola no cumprimento de uma finalidade que a sociedade lhe atribui.

A segunda vertente tem relação com o papel que simultaneamente a linguagem escrita desempenha no contexto escolar, constituindo-se como veículo privilegiado da comunicação pedagógica, quer consideremos a dimensão da transmissão dos saberes, quer a da sua explicitação por parte dos alunos, nomeadamente nas situações de avaliação que têm lugar no contexto da escola. Pela escrita passa grande parte da avaliação a que os alunos se submetem, do que se pode inferir que a obtenção de bons resultados escolares dependerá não só da posse do conhecimento adquirido, mas também da capacidade de veiculá-lo por escrito.

Uma nova perspetiva da escrita no contexto da escola vem emergindo nos últimos tempos, baseada no reconhecimento do papel relevante que ela pode desempenhar nos processos de aquisição, elaboração e expressão do conhecimento, constituindo-se como um fator determinante da qualidade da aprendizagem. Neste sentido, podemos olhá-la como ferramenta de aprendizagem. É o que fazemos neste texto, no qual daremos conta de um estudo realizado ao nível do ensino básico ( $1^{\circ}$, $2^{\circ}$ e $3^{\circ}$ ciclos) em Portugal.

\section{ESCRITA E APRENDIZAGEM}

Discutir o papel da escrita nos processos de construção e elaboração de conhecimento implica reflexão sobre o conceito de aprendizagem, considerando-se a natureza dos saberes a que dá acesso e os usos que o aprendente deles fará, bem como o próprio processo de aprendizagem e as transformações que, por meio dele, se operam no sujeito.

No que se refere à natureza dos saberes resultantes da aprendizagem, podemos considerar os de natureza procedimental, que têm relação com o saber-fazer, e os de natureza semântica ou declarativa, pelos quais o aluno aprende ou apreende um determinado objeto, revelado no conhecimento que a sociedade já conseguiu disponibilizar sobre ele.

Contrariamente ao que acontece em relação aos saberes procedimentais, referentes a competências que o aluno deve poder aplicar na vida escolar, e para além dela, no espaço e no tempo, a aprendizagem dos saberes declarativos é muitas vezes encarada como um processo no qual "o aluno é visto como a etapa no final da cadeia de difusão desse conhecimento, não sendo reconhecido como produtor de conhecimentos" (Barbeiro, 2003, p. 32). Em muitas circunstâncias, a escola pede-lhe apenas "que seja capaz de manifestar perante o professor o conhecimento que este lhe ensinou" (idem, p. 192). 
Aprender algo sobre um determinado objeto deve, todavia, ser mais do que a simples receção e acumulação do saber transmitido. Pelo contrário, aprender poderá conduzir a uma reconstrução do conhecimento, reprocessado pelo sujeito com base na sua experiência presente e passada, à luz da qual adquire um sentido próprio (Jewitt, 2006). É nesse processo de reconstrução de conhecimento que a escrita desempenha um papel relevante, enquanto instrumento de mediação na relação entre o sujeito que aprende e o objeto aprendido.

O papel da escrita na (re)construção do conhecimento pode ser compreendido com base em perspetivas diferenciadas. Quer partamos da análise das características da linguagem escrita e da comunicação por escrito, com as implicações que delas decorrem em termos de desenvolvimento intelectual, quer encaremos a escrita como processo cognitivo, quer a vejamos como prática social e cultural, podemos reconhecer o seu contributo para o sucesso na aprendizagem. Para além de potenciar a consideração do real na sua ausência, a escrita facilita a geração e o aprofundamento das ideias, permite o seu enquadramento numa forma de expressão adequada (géneros textuais) e a sua reestruturação à luz de fatores que relevam da dimensão retórica (objetivos, destinatário etc.), tornando possível a inserção em contextos diferenciados.

A conceção de escrita como ferramenta de aprendizagem encontra, desde logo, fundamento em autores diversos, como, por exemplo, Janet Emig (1977), Margaret Martlew (1983), Arthur Applebee (1984) ou David Olson (1995), que consideram o recurso à linguagem escrita como um fator de maturação cognitiva, propiciando uma maior estruturação do pensamento e, em consequência disso, o desenvolvimento do raciocínio de natureza lógico-formal. Por um lado, a escrita facilita a reflexão sobre as ideias e sobre a linguagem que, plasmadas no papel ou no ecrã, se tornam concretas e permanentes. Por outro lado, a comunicação escrita, temporal e espacialmente diferida, na maior parte dos casos, pressupõe a consideração do real na sua ausência e a sua representação sob a forma de linguagem. Como salienta Lev Vygotsky (1979), a escrita constitui uma forma de discurso mais elaborada, em que a comunicação, na falta de apoios situacionais, assenta quase exclusivamente nas palavras. Não existindo um contexto experiencial compartilhado que funcione como marco de referência implícito, torna-se "indispensável a criação explícita, por meios linguísticos, de marcos de referência internos que possam garantir a autonomização do texto em relação ao momento e circunstâncias concretas da sua produção" (Fonseca, 1994, p. 159).

A questão do contributo da escrita para a aprendizagem pode ser também perspetivada à luz de modelos do processo de escrita, como o de Linda Flower e John Hayes (1981), que concebe o ato de escrita como uma tarefa de resolução de problemas, no quadro da qual planificação, redação e revisão emergem como subprocessos primordiais. No âmbito de qualquer deles, é possível enquadrar um conjunto de tarefas favorecedoras da aprendizagem. A planificação pressupõe a mobilização dos conhecimentos, a sua ativação na memória do escrevente, a seleção e organização das ideias, em virtude dos objetivos do ato de escrita e do destinatário 
da mensagem. A redação implica a transformação de uma representação mental da realidade numa outra forma de representação dessa realidade, a linguagem verbal, o que tem implicações de natureza vária, quer em termos do grau de explicitação exigido, quer no que concerne à organização das ideias a transmitir. Passa-se do nível do discurso interior, que se caracteriza pela sua sintaxe própria, aparentemente desconexa, incompleta e com tendência para a elipse e a predicação, para um nível em que a significação depende, exclusivamente, das palavras e suas combinações (Vygotsky, 1979).Tal pressupõe a colocação numa ordem linear de informação que raramente apresenta tal estruturação, o que exige não só a capacidade de relacionar diferentes ideias num plano mental, mas também o uso adequado dos mecanismos linguísticos que permitem a sua expressão de forma sequencial. A revisão, por seu lado, exige a capacidade de refletir sobre o texto e de avaliá-lo à luz de diferentes parâmetros, num ato de distanciamento do indivíduo em relação ao produto do seu trabalho.

A capacidade de elaborar a informação recolhida da memória, transformando-a no sentido de a adequar ao contexto comunicativo, é apontada por Carl Bereiter e Marlene Scardamalia (1987) como característica da escrita desenvolvida, configurada num modelo que designam de transformação de conhecimento (knowledge-transforming). Esses autores distinguem essa escrita adulta da escrita em desenvolvimento, associando esta última a um modelo de explicitação de conhecimento (knowledge-telling). O que caracterizará a escrita menos desenvolvida é o menor grau de elaboração da informação à medida que vai sendo ativada na memória, funcionando a associação de ideias como o principal fator de geração de conteúdo. Neste quadro, a definição de objetivos comunicativos pode constituir uma importante estratégia para levar o aluno a transformar o conhecimento por meio da escrita, ao tentar adequar o texto à consecução desses objetivos. Tal exige a reflexão, a consideração do ponto de vista do destinatário, a procura de vias para a resolução de problemas, quer em relação à linguagem, quer em relação ao conteúdo, o que leva à reformulação, ao desencadear de novas possibilidades que vão sendo criadas no próprio processo.

O contributo da escrita para a promoção da aprendizagem assenta em fatores diversos. Léonard Rivard (1994) destaca os desafios cognitivos colocados pela complexidade da tarefa, pela necessidade de consciencializar os processos tendo em vista a seleção das estratégias apropriadas e pela exigência de conceptualização do conhecimento de natureza factual. Para este autor, a complexidade inerente ao processo de escrita, que obriga os alunos a elaborar sobre o aprendido, a reprocessar conceitos e ideias, a colocar hipóteses, a interpretar e sintetizar, a confrontar ideias, promove necessariamente a emergência de estratégias cognitivas mais complexas.

Da mesma forma, Perry Klein (1999) alude a fatores de natureza cognitiva quando discute a escrita como ferramenta de aprendizagem: a escrita permite estruturar o pensamento e, pela explicitação das ideias, aprofunda a compreensão; a escrita facilita a reformulação e o aprofundamento de ideias baseados num processo 
de sucessivas revisões dos textos, à medida que vão sendo produzidos. Também para Bonnie Armbruster et al. (2005), a escrita contribui para a promoção da aprendizagem, podendo ser usada para desenvolver conceitos, generalizar, promover o pensamento crítico e a resolução de problemas, refletir sobre o próprio processo de compreensão.

Para que a escrita possa constituir uma ferramenta de aprendizagem eficaz, é necessário que o aluno vença o desafio da complexidade da tarefa. A eficácia da escrita na construção da aprendizagem depende de certos fatores que devem ser considerados como, segundo Päivi Tynjälä et al. (2001), o envolvimento dos alunos na tarefa de transformação do conhecimento, a implicação dos conhecimentos prévios dos alunos nas tarefas, a reflexão destes sobre as suas próprias experiências.

Também a perspetiva sociocognitiva, que atende aos contextos da comunicação e da aprendizagem e valoriza, para além da situação imediata de produção, os aspetos sociais e culturais que condicionam as formas de usar a linguagem, fundamenta o contributo da escrita para a construção do conhecimento. A noção de contexto assume, nesta perspetiva, um lugar de relevo, seja ele entendido como situação, "realidade objetiva que condiciona a produção textual", quer o vejamos como comunidade discursiva, "contexto partilhado que torna possível dar sentido e interpretar textos" ou como esfera de atividade, no âmbito da qual "os textos são resultado e, ao mesmo tempo, instrumento de mediação na construção do diálogo como processo cultural" (Camps, 2005, p. 17).

Neste enquadramento, tendo em conta a componente discursiva das ações humanas, adquire relevo a questão dos géneros discursivos, entendidos como "formas de enunciados mais ou menos estáveis que configuram e são configurados pelas pessoas que partilham o mesmo contexto de comunicação" (idem, p. 21). A necessidade de configurar o conhecimento no quadro de um determinado género pode constituir fator de aprendizagem pelo uso da escrita. Tal é referido por Klein (1999), que, para além dos fatores de natureza cognitiva que fazem da escrita uma ferramenta de aprendizagem e de que anteriormente demos conta, considera também fatores decorrentes da dimensão discursiva. Ante a necessidade de configurar o conhecimento no quadro de géneros textuais com características específicas, o aprendente tem de articular forma e conteúdo e de considerar a dimensão retórica, que implica definição de objetivos e adequação do texto a um destinatário. $\mathrm{Na}$ mesma linha de pensamento, Rivard (1994) considerara a formatação do conhecimento numa determinada tipologia textual como um dos aspetos favorecedores da aprendizagem pelo uso da escrita. Do mesmo modo, Brian Hand e Vaughan Prain (2002) valorizam o papel da escrita na promoção do conhecimento de natureza conceptual e da aprendizagem, na medida em que obriga o aluno a dar resposta às expectativas, convenções e formas de raciocínio próprias de uma determinada comunidade científica.

O uso da escrita para representar e comunicar o conhecimento pressupõe assim o domínio dos padrões utilizados por uma determinada comunidade para dar forma ao conhecimento próprio da sua área. Como salienta Carey Jewitt (2006), 
a aprendizagem, no quadro de um determinado campo de saber, envolve não só a aquisição de conceitos específicos, mas também a interiorização dos meios de representar e comunicar o conhecimento próprio desse campo, isto é, a assunção da identidade e do discurso do especialista.

Os diferentes géneros textuais desempenham, portanto, um relevante papel na representação e transmissão de conhecimento, decorrendo o seu uso das funções que podem desempenhar. Instrumento de mediação que modela a relação com o objeto de conhecimento, cada género encerra um conjunto de potencialidades e de exigências com reflexos no próprio processo da sua construção e no modo como representam o conhecimento. À diversidade de géneros, tanto de natureza não compositiva como de natureza compositiva, corresponderá a uma diversidade de instrumentos linguísticos de mediação e de objetos/objetivos de conhecimento alcançáveis na atividade de aprendizagem: as notas tomadas por meio de uma exposição oral, a ficha de leitura correspondente à consulta de uma fonte escrita, o esquema ou diagrama que sintetiza o conhecimento construído com base em fontes múltiplas, o preenchimento de espaços em frases ou textos pré-formatados, a elaboração de respostas a questões, a produção de um texto integrado numa situação de comunicação em que os alunos participem são tarefas que mobilizam diferentes artefactos de conhecimento e de tomadas de decisão, quer em relação ao conteúdo, quer em relação à sua representação linguística (Carvalho et al., 2008).

As potencialidades da escrita enquanto ferramenta de aprendizagem alargam-se quando consideramos que, para além de constituir uma forma de configurar o conhecimento, a escrita facilita a reflexão sobre o próprio processo de construção desse conhecimento. $\mathrm{O}$ registo desse processo, em diários de aprendizagem, notas de campo, portefólios de percurso, balanços de aprendizagem etc., possibilita a tomada de consciência dos passos dados e do que estes permitem alcançar. Pelo nível de explicitação que exige, pela autonomização em relação à situação de enunciação, pela reflexão e reformulação que desencadeia, a escrita constitui um instrumento privilegiado para essa evolução.

A escrita, perspetivada como ferramenta de aprendizagem, tem sido objeto de atenção em vários contextos e momentos. Pelo relevo que assumiram, destacamos dois: o movimento Writing Across the Curriculum (WAC), desenvolvido nos Estados Unidos a partir da década de 1970, que, assumindo a escrita, simultaneamente, como meio de comunicação e como meio de aprendizagem, entende que ela não é um objeto a tratar apenas na aula de língua, sendo, muito pelo contrário, uma questão transversal a toda a escola, independentemente do nível de ensino (Tynjälä et al., 2001); o Science Writing Heuristic (SWH), que, no contexto do ensino das ciências, vem adquirindo particular relevo na investigação sobre as potencialidades pedagógicas que decorrem do uso da escrita nos processos de aquisição, elaboração e comunicação do conhecimento científico.

O papel que a escrita pode desempenhar nos processos de aquisição, elaboração e transmissão do conhecimento é também reconhecido em documentos 
de caráter regulador que, desde a reforma programática de 1991, têm vindo a ser emanados do Ministério da Educação em Portugal (Portugal, 2001; Sim-Sim et al.1997). Pela análise das características da escrita enquanto linguagem e no reconhecimento do caráter complexo e multifacetado de seu processo, aí se destaca o papel que ela desempenha nos processos de construção e, sobretudo, de expressão do conhecimento, com implicações na maioria das situações de avaliação.

Relevando a importância da linguagem verbal nos processos de estruturação do pensamento, esses documentos perspetivam a escrita como competência transversal em relação às várias disciplinas escolares, considerando-a uma ferramenta de aprendizagem, cujo domínio constitui um importante fator de sucesso escolar. Nessa lógica, assume-se a escrita como uma competência multifuncional: propõe-se que o aluno não só domine as técnicas de composição de diversos tipos de texto, mas também desenvolva capacidades de escrita de caráter não compositivo, como o registo e a tomada de notas, essenciais a um bom desempenho acadêmico. Concretizando um pouco mais, defende-se que, no final do ensino básico, para além de escreverem, com correção ortográfica, diversidade sintática e vocabulário rico, diferentes tipos de texto, respondendo a objetivos comunicativos diferenciados, os alunos devem ser capazes de

dominar as técnicas de escrita compositiva para elaboração de conhecimento, redigir projetos de trabalho, resumir textos informativos e reduzir um texto a esquema, escrever notas a partir de textos lidos ou de comunicações orais, para reter informação ou para a reorganizar e de usar a escrita como forma de organização do pensamento. (Sim-Sim et al., 1997, p. 81)

Se é inegável, à luz dos fundamentos apresentados, que a escrita pode constituir um contributo relevante para a promoção da aprendizagem, também é verdade que tal contributo depende, em larga escala, do modo como as tarefas que a envolvem no quadro de atividades de aprendizagem são desenvolvidas, disso dependendo a qualidade do próprio processo de aprendizagem traduzida numa maior ou menor apropriação do objeto de conhecimento por parte do aprendente.

De facto, o recurso à escrita pode simplesmente servir para reproduzir, tal qual, o conhecimento recebido de qualquer fonte, oral ou escrita, seja ela a exposição feita pelo professor, o manual escolar, um livro ou um artigo científico. Pode, pelo contrário, instituir um complexo processo de resolução de problemas, no quadro do qual o aluno, incorporando objetivos de natureza comunicativa, ao mesmo tempo em que organiza o conhecimento de forma própria, torna-se capaz de transmiti-lo de forma adequada em razão de contextos diferenciados. Esta capacidade de veicular conhecimento de forma apropriada ao contexto de comunicação consubstancia-se, por um lado, num aprofundamento do conhecimento em causa e, por outro, numa maior competência de escrita, evidenciada tanto no plano da realização da tarefa como no do produto que dela resulta (Carvalho et al., 2008). 


\section{ESTUDOS}

Assumindo a importância que a escrita pode desempenhar no âmbito dos processos de aquisição, elaboração e expressão de conhecimento no contexto da escola, importância essa reconhecida, como referimos, no currículo oficial desde há quase duas décadas, pareceu-nos relevante realizar um estudo com o objetivo de verificar até que ponto esta dimensão é valorizada na escola portuguesa ao nível do ensino básico, que tem a duração de nove anos, compreendendo um primeiro ciclo de quatro anos, um segundo de dois e um terceiro de três.

Interessando-nos a escrita enquanto ferramenta de aprendizagem e não enquanto objeto de aprendizagem. Não consideramos neste estudo as disciplinas de língua, no quadro das quais a escrita assume o estatuto de conteúdo/objeto de aprendizagem. Escolhemos, assim, as disciplinas de história, ciências naturais, ciências físico-químicas e geografia e, ao nível do $1^{\circ}$ ciclo, a área disciplinar que integra esses domínios do saber, intitulada estudo do meio.

Definidas as áreas disciplinares a estudar, optámos por dois percursos metodológicos distintos, mas complementares: a análise de manuais escolares e um inquérito a professores por meio de questionário.

\section{A ANÁLISE DE MANUAIS ESCOLARES}

Os manuais escolares, textos reguladores das práticas de ensino-aprendizagem, constituem uma importante fonte de conhecimento do que acontece na sala de aula e das conceções subjacentes às práticas pedagógicas (Castro, 1995; Choppin, 1992).

A questão central, subjacente à análise, foi a seguinte: o recurso à escrita sugerido nos manuais potencia a elaboração e reconstrução do conhecimento por parte do aluno ou, simplesmente, promove a reprodução de informação/ conhecimento veiculada no próprio manual? Incluímos na primeira dimensão, de elaboração e reconstrução do conhecimento, as propostas de atividades que suscitam transformações com base na assunção do novo conhecimento por parte do sujeito, transformações essas que afetam a sua perspetiva perante os fenómenos com manifestação no próprio discurso, pelo acesso a novos significados e conceitos, os quais alargam o leque de possibilidades para falar acerca desses fenómenos, para descrevê-los, para comunicá-los aos outros, para integrá-los num contexto específico (que inclui o contexto do aluno, designadamente o contexto em que a aprendizagem desses fenómenos tem lugar). Como atividade de reprodução de conhecimento, consideramos as que reduzem a tarefa do aluno à mera deteção da informação em documentos fornecidos e à explicitação desse conhecimento em moldes, na maior parte dos casos, pré-formatados, com o objetivo de assegurar e verificar que o conhecimento em causa foi transposto para o aluno.

$\mathrm{Na}$ resposta à questão essencial que se colocava, o trabalho de análise levado a cabo seguiu percursos metodológicos e perspetivas de análise diferenciados.

A análise dos manuais do $1^{\circ}$ ciclo colocou a questão no cruzamento de três linhas de análise: a) a escrita enquanto representação do conhecimento; b) a 
colocação de objetivos comunicativos para os documentos produzidos pelos alunos; c) a ativação da dimensão metacognitiva pela expressão, por meio da escrita, do processo de aprendizagem.

No que se refere aos manuais do $3^{\circ}$ ciclo, a análise incidiu sobre um total de 12 manuais das quatro disciplinas aqui referidas, sendo a dicotomia reprodução/ elaboração e reconstrução do conhecimento implicada diretamente na classificação das tarefas que pressupunham um recurso à expressão escrita.

\section{Os manuais do $1^{\circ}$ ciclo do ensino básico}

A análise dos manuais do $1^{\circ}$ ciclo do ensino básico, realizada sobre um corpus de oito manuais de estudo do meio, procurou, assim, responder à questão central referida (reprodução ou elaboração e reconstrução do conhecimento) com base em três dimensões de análise.

A primeira linha de análise - a escrita enquanto representação do conhecimento - centra-se na oposição entre propostas de exercícios e atividades que solicitam respostas escritas segundo moldes pré-formatados (como respostas a questionários dirigidos ao conteúdo do tópico exposto, preenchimento de lacunas, identificação de elementos em figuras etc.) e propostas em que está em causa a construção de um texto por parte do aluno. Essa oposição pode relacionar-se com a distinção entre escrita não compositiva e escrita compositiva (Grabe; Kaplan, 1996). Enquanto no primeiro caso o aluno se limita a vazar o conhecimento num molde fornecido (questionário, frase, legendas), no segundo caso, o aluno é chamado a reconstruir o conhecimento numa unidade textual, que ele próprio deverá organizar, para representar o conhecimento de forma coesa e coerente, e que deverá existir enquanto unidade autónoma perante o leitor. Nesse segundo caso, a atividade está a incluir a dimensão em que o aluno deverá aceder ao discurso como parte integrante da aprendizagem, para representar o conhecimento e para comunicá-lo (Jewitt, 2006). Os objetivos a alcançar na aprendizagem incluem não apenas a capacidade de evocação e repetição dos conteúdos, mas também a capacidade de mobilização desses conteúdos na elaboração de um discurso por parte dos sujeitos.

A escrita compositiva confronta os alunos com exigências de representação do conhecimento, designadamente em relação à sua organização, na unidade global que é o texto, e em relação à sua expressão, ao longo do texto, de uma forma articulada. Ao fazê-lo, o aluno relaciona-se de uma forma mais profunda com o conhecimento que é objeto de aprendizagem. Deverá moldá-lo, considerar as suas diversas componentes para organizá-las (eventualmente tendo procedido à seleção de aspetos relevantes), distribuindo-as ao longo do texto, e encontrar uma expressão linguística que se mantenha fiel ao conhecimento representado.

A existência do texto (para entregar ao professor) pode constituir o fim da atividade. Contudo, o texto construído pode também ser transformado num instrumento que faculte ao aluno acesso a papéis sociais ligados ao conhecimento. Isso acontece quando ao texto específico são associados objetivos que não se limitem à entrega ao professor. Retomando a posição de Jewitt (2006), se a construção do 
texto liga a aprendizagem ao domínio do discurso relacionado com determinada área, a ativação de objetivos comunicativos constitui um meio de ligar a aprendizagem à assunção da identidade de conhecedor de determinado domínio do saber. A existência de propostas que ativem esta dimensão comunicativa e de identidade constituiu a segunda linha de análise - a colocação de objetivos comunicativos para os documentos produzidos pelos alunos.

Finalmente, a terceira linha de análise - a ativação da dimensão metacognitiva pela expressão, por meio da escrita, do processo de aprendizagem - baseia-se no poder da escrita para explicitar não apenas o objeto do conhecimento, mas também o próprio processo pelo qual o sujeito constrói o conhecimento acerca desse objeto. Por meio da expressão do processo, o aluno liga o conhecimento do objeto a si próprio, enquanto sujeito aprendente, toma consciência das dificuldades encontradas, dos progressos e transformações realizadas ao longo de um percurso e pode confrontar as suas vivências com as dos seus colegas, mobilizando também a vertente colaborativa em relação aos seus pares, que são colegas de aprendizagem.

A análise efetuada segundo as linhas de indagação adotadas encontrou os resultados apresentados no Quadro 1.

Quadro 1- Análise dos manuais de estudo do meio do $1^{\circ}$ ciclo do ensino básico

\begin{tabular}{|l|l|r|r|r|r|}
\hline \multicolumn{2}{|c|}{ Linhas de análise } & \multicolumn{2}{c|}{ Tarefas } & \multicolumn{2}{c|}{ Unidades } \\
\hline \multirow{2}{*}{ 1. Dimensão compositiva } & Escrita não compositiva & 1.293 & $95 \%$ & 41 & $55 \%$ \\
\cline { 2 - 6 } & Com escrita compositiva & 73 & $5 \%$ & 33 & $45 \%$ \\
\hline \multirow{2}{*}{ 2. Dimensão comunicativa } & $\begin{array}{l}\text { Com propostas de } \\
\text { comunicação/ divulgação }\end{array}$ & 30 & $41 \%$ & 16 & $39 \%$ \\
\cline { 2 - 6 } & $\begin{array}{l}\text { Sem propostas de } \\
\text { comunicação/ divulgação }\end{array}$ & 43 & $59 \%$ & 25 & $61 \%$ \\
\hline \multirow{2}{*}{$\begin{array}{l}\text { 3. Dimensão metacognitiva/ } \\
\text { metaprocessual }\end{array}$} & $\begin{array}{l}\text { Com propostas de } \\
\text { escrita metacognitiva }\end{array}$ & - & $0 \%$ & - & $0 \%$ \\
\cline { 2 - 6 } & $\begin{array}{l}\text { Sem propostas de } \\
\text { escrita metacognitiva }\end{array}$ & 73 & $100 \%$ & 41 & $100 \%$ \\
\hline
\end{tabular}

Fonte: Dados da pesquisa.

Elaboração dos autores.

Os resultados mostram que a construção da aprendizagem, por meio das propostas dos manuais de estudo do meio, tem por base a escrita não compositiva (respostas a questionários, completamento de frases, legendagem de figuras etc.). Dado que a escrita não compositiva se desdobra num elevado número de itens, designadamente por meio de questionários com diversas questões, e a solicitação de escrita compositiva corresponde, de um modo geral, a um item adicional integrado no conjunto das questões, tomámos também como base de análise cada uma das unidades ou blocos didáticos em que se encontram organizados os manuais. O objetivo foi verificar a existência ou não em cada unidade de propostas de escrita compositiva. Nesse caso, o desnível atenua-se, mas existe ainda um número alargado de unidades em que não estão presentes tarefas de escrita compositiva (55\%, como se observa no Quadro 1).

Em relação à dimensão comunicativa, ela encontra-se presente nalguns manuais de uma forma mais ou menos sistematizada. Assim, enquanto um manual 
(M1) apresenta propostas orientadas para a divulgação, de uma forma bastante regular, noutros as propostas surgem de forma mais escassa (sobretudo nas unidades correspondentes à caracterização do meio local) e há três manuais em que não ocorrem. Nas propostas apresentadas, encontramos referências, enquanto meios de divulgação, ao jornal escolar, à organização de exposições, à constituição de dossiês temáticos na turma, à realização de apresentações aos colegas e também à mobilização das tecnologias de informação e comunicação, não apenas como meios de pesquisa, mas também como meio de divulgação, com a colocação dos documentos produzidos na página da escola na Internet ou com o envio da informação recolhida aos alunos de outras escolas por $e$-mail.

A dimensão metacognitiva, no que respeita à expressão, por meio de escrita, do próprio processo de aprendizagem vivido pelos alunos está ausente das propostas dos manuais escolares analisados. Como seria de esperar, estes apresentam propostas de realização de experiências, designadamente nas seções dedicadas à "descoberta do ambiente natural" e à "descoberta dos materiais e objetos": experiências com sementes e o seu processo de germinação, com a luz, com ímanes, com alavancas e roldanas, com elásticos etc. Essas propostas incluem nos próprios manuais os espaços e linhas para que o aluno vá procedendo ao registro das observações e conclusões. A adoção exclusiva dessa metodologia de trabalho afasta a escrita compositiva por meio do relato da experiência, que poderia assumir uma função integradora da experiência realizada e da aprendizagem. Pela presença que vai deter ao longo da vida escolar, esse género textual poderia seria trabalhado logo desde o $1^{\circ}$ ciclo do ensino básico (Pereira, 2007).

Para além do género textual correspondente ao relato de experiência, em que o objetivo a longo prazo consistirá na aproximação ao relato científico, a dimensão metacognitiva pode mobilizar outros géneros mais diretamente ligados à vivência da própria aprendizagem: os diários de aprendizagem, a escrita livre ou exploratória, para ativar conhecimentos prévios e ligações ao contexto dos alunos, os balanços de aprendizagem após o tratamento do conteúdo estudado etc. Esses géneros apresentam a possibilidade de consciencializar, por meio da escrita, não só os conteúdos, mas também o percurso de aprendizagem. Neles, a "experiência" passa a ser também "experiência de aprendizagem". Em termos discursivos, esses géneros situam-se a meio caminho entre a linguagem interior - "linguagem para si”, na expressão de Vygotsky (1979) - e a linguagem dos géneros científicos, como a que se encontra nos relatórios de experiências científicas ou nos textos expositivos de determinada matéria. Em contraste com estes, os géneros de escrita relativos às experiências de aprendizagem são geralmente escritos na primeira pessoa, quer individual, quer coletiva. Contudo, como Jacques Crinon (2000) coloca em relevo, esta presença do sujeito favorece a sua ligação aos saberes, situa-o na sua própria atividade de aprendizagem, incrementando a tomada de consciência das questões encontradas no percurso e dos passos dados para o conhecimento. Enquanto "escritos intermediários", manifestam ainda os traços das atividades realizadas e os transformam em instrumentos de aprendizagem (idem, p. 62). 
Análise de manuais do $3^{\circ}$ ciclo do ensino básico

No nível do $3^{\circ}$ ciclo do ensino básico, a análise recaiu num conjunto de 12 manuais das disciplinas curriculares de ciências físico-químicas (CFQ), ciências naturais $(\mathrm{CN})$, geografia $(\mathrm{G})$ e história $(\mathrm{H})$. No caso das três primeiras, foram analisados três manuais de cada disciplina do $7^{\circ}$ ano de escolaridade. No caso da disciplina de história, foram analisados dois manuais do $8^{\circ}$ e um do $7^{\circ}$ ano. A análise consistiu na identificação e classificação de todas as atividades que, explícita ou implicitamente, pressupunham o recurso à escrita, distinguindo as situações em que as tarefas propostas procuravam aproveitar o recurso à linguagem escrita para elaboração e reconstrução do conhecimento e aquelas em que tal linguagem era meramente utilizada para reprodução do conhecimento.

Incluímos nessa última categoria as atividades que pressupunha apenas que o aluno reproduzia informação disponível no próprio manual. Essas atividades visam normalmente verificar até que ponto o aluno consegue verbalizar por escrito o conhecimento-alvo, podendo as respostas às questões que são colocadas ser encontradas na própria página ou em páginas adjacentes. Constituem exemplos de atividades dessa natureza as que pedem a definição de conceitos explicitados numa secção, muitas vezes da mesma página.

Pelo contrário, considerámos como de elaboração e reconstrução do conhecimento as atividades em que o uso da escrita implicava outra atividade cognitiva, para além da mera localização da informação no manual e da sua reprodução noutro local. Incluíram-se nessa categoria atividades de registo, de tomada de notas, de síntese, de elaboração de esquemas e diagramas integrando informação proveniente de fontes diversas etc.

Uma tarefa que solicita ao aluno que redija um texto no qual explique um esquema, ou uma outra em que o aluno é convidado a registar o que vai observando no decurso de uma experiência ou demonstração podem incluir-se nessa categoria.

Os resultados da análise efetuada ao conjunto dos manuais constam no Quadro 2 e demonstram um predomínio claro das atividades favorecedoras da reprodução do conhecimento.

Quadro 2-Análise dos manuais de $\mathrm{CFQ}, \mathrm{CN}, \mathrm{G} \mathrm{e} \mathrm{H}$ do $3^{\circ}$ ciclo do ensino básico

\begin{tabular}{|l|r|r|r|r|}
\hline \multicolumn{1}{|c|}{ Disciplina } & \multicolumn{2}{|c|}{$\begin{array}{c}\text { Reprodução do } \\
\text { Conhecimento }\end{array}$} & \multicolumn{2}{c|}{$\begin{array}{r}\text { Elaboração e Reconstrução } \\
\text { do Conhecimento }\end{array}$} \\
\hline Ciências físico-químicas & 677 & $81 \%$ & 159 & $19 \%$ \\
\hline Ciências naturais & 572 & $79 \%$ & 149 & $21 \%$ \\
\hline Geografia & 1.481 & $96 \%$ & 58 & $4 \%$ \\
\hline História & 1.069 & $87 \%$ & 155 & $13 \%$ \\
\hline
\end{tabular}

Fonte: Dados da pesquisa.

Elaboração dos autores.

Em suma, a análise das tarefas de escrita nos manuais dos dois ciclos revelou uma presença reduzida das dimensões compositiva e comunicativa e a ausência da 
dimensão metacognitiva, predominando claramente as atividades de reprodução do conhecimento, em detrimento das atividades potenciadoras da elaboração e reconstrução do conhecimento. Os resultados chamam a atenção para o papel que, para além do manual, cabe ao professor. Consciente do alcance e das limitações do manual, cabe ao professor ativar dimensões que poderão desempenhar um papel importante na aprendizagem, para além das propostas do manual. A análise efetuada revelou que a ligação que os manuais escolares estabelecem entre a escrita e a aprendizagem fica muito limitada ao universo do próprio manual. Na verdade, a escrita é mobilizada predominantemente para que o aluno inscreva as suas respostas de reprodução do conhecimento anteriormente apresentado pelo manual nos locais pré-formatados para o efeito, em termos espaciais, organizacionais e discursivos, por meio de questionários. $\mathrm{O}$ formato do questionário desempenha um papel de base em relação à construção da aprendizagem. Ele ativa ou recupera o conhecimento, modela-o, organiza-o numa rede de relações. No entanto, para que o aluno aceda ao desempenho de funções por meio da escrita, torna-se necessário não apenas que seja capaz de inscrever as respostas no questionário, mas também que seja capaz de produzir textos escritos, que possam adquirir autonomia em relação ao manual.

A autonomia alcançada em relação ao manual permite integrar os textos ou documentos multimodais produzidos em novos contextos de realização de funções, dentro da comunidade da turma ou para além dela. Algumas das propostas encontradas constituem passos no sentido dessa autonomia, ao sugerirem a escrita de textos com base nas observações e na recolha de informação realizadas sobre determinado tema e, nalguns casos, ao sugerirem a atribuição de funções comunicativas aos documentos produzidos. Nos casos em que isso não acontece, cabe ao professor a iniciativa de integrar na aprendizagem as dimensões compositiva, comunicativa e também metacognitiva.

INQUÉRITO

Outra vertente deste estudo consistiu num inquérito a professores de diferentes disciplinas, excluindo as da área das línguas, pelas razões que anteriormente foram expostas para justificar a seleção das disciplinas cujos manuais foram objeto de análise. $\mathrm{O}$ inquérito visou à recolha de informação que pudesse ser confrontada com a que emergiu das análises dos manuais que acabámos de descrever. A opção por este caminho metodológico decorre da constatação de que a natureza de qualquer atividade e as potencialidades que ela encerra dependem, em larga escala, do modo como o professor a operacionaliza. Ao mesmo tempo em que nos interessava conhecer o tipo de atividades que envolvem o recurso à escrita implementadas em aulas das disciplinas já referidas, visávamos, também, saber até que ponto pelo recurso à escrita se construía e elaborava o conhecimento ou se, pelo contrário, se fazia uso da escrita para a sua mera reprodução.

O questionário elaborado integrava uma única questão, de resposta aberta, formulada nos seguintes termos: 
Em que situações, no âmbito da sua disciplina (aula ou trabalho de casa), é que os seus alunos recorrem à Escrita? Exemplifique sempre que considere oportuno.

Distribuído entre os meses de setembro e novembro de 2006, o inquérito foi respondido por 64 professores das disciplinas referidas, todos eles docentes do $3^{\circ}$ ciclo do ensino básico, em exercício em escolas do distrito de Braga.

Com base nas respostas, foi possível definir, a posteriori, um conjunto de categorias englobando os diferentes tipos de tarefas de escrita descritos pelos respondentes. Essas categorias, em número de 14 (Quadro 3), remetem para tarefas de natureza muito diversa, algumas delas não implicando mais que o registo ou a cópia de informação simples, outras exigindo um maior grau de elaboração. A distribuição das atividades de escrita no contexto das referidas disciplinas pelas 14 categorias apuradas refere-se, num primeiro filtro de análise, a padrões de frequência relativamente ao número total de respondentes (64), e, num segundo, à sua percentagem relativamente ao número total de atividades referidas (268).

Quadro 3-Atividades de escrita realizadas em contexto de prática pedagógica

\begin{tabular}{|l|r|r|}
\hline \multicolumn{1}{|c|}{ Atividades } & $\begin{array}{r}\text { Frequência relativamente } \\
\text { ao número total de } \\
\text { respondentes (64) }\end{array}$ & $\begin{array}{l}\text { Percentagem relativamente } \\
\text { ao número total de } \\
\text { atividades referidas (268) }\end{array}$ \\
\hline Testes escritos/avaliação & 43 & $16,0 \%$ \\
\hline $\begin{array}{l}\text { Ditado/registo de informação } \\
\text { no quadro/caderno diário }\end{array}$ & 38 & $14,2 \%$ \\
\hline $\begin{array}{l}\text { Relatórios de atividades } \\
\text { laboratoriais e de campo }\end{array}$ & 16 & $6,0 \%$ \\
\hline $\begin{array}{l}\text { Trabalhos de pesquisa com } \\
\text { base em fontes escritas }\end{array}$ & 33 & $12,3 \%$ \\
\hline Resumos/sínteses & 29 & $10,8 \%$ \\
\hline Esquemas e mapas conceptuais & 22 & $8,2 \%$ \\
\hline Resolução de fichas de trabalho & 43 & $16,0 \%$ \\
\hline Elaboração de fichas de leitura & 1 & $0,4 \%$ \\
\hline Glossários de termos & 4 & $1,5 \%$ \\
\hline $\begin{array}{l}\text { Produção de textos (composições, } \\
\text { diários, escrita criativa) }\end{array}$ & 8 & $3,0 \%$ \\
\hline $\begin{array}{l}\text { Redação do sumário da } \\
\text { aula pelos alunos }\end{array}$ & 9 & $3,4 \%$ \\
\hline Análise de documentos & 12 & $4,5 \%$ \\
\hline Elaboração de textos para divulgação & 4 & $1,5 \%$ \\
\hline $\begin{array}{l}\text { Outros (auto e heteroavaliação, } \\
\text { ortografia; punição) }\end{array}$ & 6 & $2,2 \%$ \\
\hline
\end{tabular}

Fonte: Dados da pesquisa.

Elaboração dos autores.

Tendo sempre como referência as 14 categorias de atividades de escrita estabelecidas, verificou-se, na análise dos dados, que o recurso à escrita no conjunto das várias disciplinas ocorre predominantemente em três situações (qualquer uma delas identificada por muito mais de metade dos professores que responderam à 
questão): testes escritos/avaliação, com 43 ocorrências num total de 64 inquéritos (67\%), correspondendo a $16 \%$ das 268 atividades referidas; resolução de fichas de trabalho, com o mesmo número de ocorrências, ou seja, em $67 \%$ dos inquéritos e os mesmos $16 \%$ do total de atividades; ditado/registos de informaçôes no quadro/caderno diário, identificada em 38 respondentes (59,4\%), representando 14,2\% do total de usos da escrita explicitados.

Se, em alguns casos, é possível determinar se uma atividade privilegia a reprodução ou a reconstrução e elaboração do conhecimento (o ditado/registos de informaçôes no quadro/caderno diário parece configurar uma atividade de reprodução de conhecimento, enquanto um relatório de uma atividade laboratorial ou de campo, uma sintese ou um resumo tenderão a constituir atividades de elaboração de conhecimento), outras há que dependem do modo como são implementadas pelo professor, pelo que a exemplificação, admitida na questão colocada, poderia ajudar à determinação da natureza da atividade. Outras atividades ainda, dada a forma como os professores as identificam (por exemplo, a resolução de fichas de trabalho), não são também passíveis de uma imediata classificação num ou noutro campo. Contudo, um conhecimento dos materiais dos quais essas fichas são habitualmente retiradas (manuais escolares, cadernos de exercícios, livros auxiliares), que decorre da investigação que sobre eles se tem realizado, permite, de algum modo, inferir sobre a sua natureza.

Analisando essas categorias e considerando as que apresentam níveis mais elevados de ocorrência, podemos, de algum modo, inferir uma tendência para um uso escolar da escrita que visa, sobretudo, à expressão ou reprodução dos saberes. Tal acontecerá nos testes de avaliação, o que não significa, obviamente, que a sua resolução tenha que passar simplesmente por tarefas de reprodução de saberes. A tendência para a reprodução do conhecimento em detrimento da elaboração deste acontecerá também na resolução de fichas de trabalho. Esta assunção decorre do conhecimento dos materiais dos quais as fichas são frequentemente recolhidas: manuais escolares e respetivos livros de apoio. No que se refere aos primeiros, as análises antes aqui descritas evidenciam o amplo predomínio das tarefas de reprodução de conhecimento. No que aos últimos diz respeito, a tendência será a mesma, como decorre da análise que João Ramos (2006, p. 112) deles faz, concluindo que, nos cadernos de apoio, as solicitações feitas ao aluno assumem unicamente a função de expressão do conhecimento. Na linha da reprodução irá também a terceira categoria mais frequente, ditado/registro de informação no quadro/caderno diário.

Consideremos agora um outro conjunto de categorias (quatro) que registam, ainda, frequências com algum significado: trabalhos de pesquisa com base em fontes escritas - 33 ocorrências nos 64 inquéritos, o que equivale a $52 \%$ de inquiridos e a $12,3 \%$ do total de 21 atividades apuradas; resumos/sinteses de conteúdos lecionados -29 ocorrências, equivalentes a $45 \%$ dos professores e 10,8\% dos usos referidos; elaboração de esquemas e mapas conceptuais - 22 ocorrências, isto é, 34\% e 8,2\% respetivamente; relatórios de atividades laboratoriais e de campo- 16 ocorrências nos 
mesmos 64 inquéritos (25\%), correspondendo a 6\% do conjunto das atividades explicitadas.

Reconhece-se claramente que os quatro tipos enunciados de tarefas de escrita constituem realizações possíveis e propícias à reconstrução e elaboração de conhecimento, sendo de registar positivamente não só o facto de elas fazerem parte das conceções dos professores sobre o processo de escrita, mas também o de constituírem, na verdade, práticas de elaboração escrita da experiência.

Todavia, para que estas atividades de escrita sejam efetivamente formas de transformação do conhecimento, é preciso atender ao contexto da sua realização e, particularmente, aos papéis que professor e alunos desempenham no momento em que elas são desenvolvidas. Com efeito, estão identificadas práticas escolares indiciadoras de que, em tarefas desta natureza, é corrente o recurso a estratégias de mera reprodução de conhecimento, tais como as que a seguir se enunciam: os resumos/sintese são, por vezes, elaborados pelos professores e ditados aos alunos, o mesmo acontecendo com os esquemas de conteúdo; os mapas de conceitos aparecem, frequentemente, em fase de construção avançada nos manuais escolares, cabendo ao aluno o simples preenchimento de espaços em branco; a realização de trabalhos de pesquisa traduz-se, em certas situações, na justaposição de informação recolhida em diferentes fontes (sobretudo na Internet), sem qualquer tipo de tratamento por parte do leitor/escrevente, sendo muito frequentemente identificadas situações de corte/colagem (copy/paste); também os relatórios de atividades laboratoriais e de campo podem confinar-se ao preenchimento de formulários previamente formatados ou fornecidos pelo próprio professor.

Por fim, apresentamos as referências que traduzem: a associação de uma carga negativa à expressão escrita, por exemplo, quando se afirma que a escrita pode servir de castigo (duas ocorrências); a valorização dos aspetos mais superficiais do processo de expressão escrita, quando, por exemplo, refere-se à correção ortográfica (duas ocorrências); a assunção de que algumas tarefas rotineiras configuram momentos de uso da escrita, de que é exemplo (em nove inquéritos) a redação do sumário da aula.

\section{NOTAS FINAIS}

Apesar de se terem identificado algumas práticas de escrita potenciadoras da sua utilização como ferramenta de aprendizagem, no contexto escolar e na maioria das situações, o uso da escrita acontece, sobretudo, no quadro de tarefas que visam à reprodução de informação, só muito raramente sendo perspetivada como facilitadora e promotora da elaboração do conhecimento. Apesar das diretivas expressas em documentos emanados do Ministério da Educação e da existência de estudos científicos que acentuam a importância da escrita no processo de aquisição, construção e expressão de conhecimento, os dados aqui apurados indiciam o predomínio de conceções e usos tradicionais da escrita, valorizando-se a expressão/reprodução de informação em detrimento da elaboração/construção de conhecimento. 
Para que a escrita possa constituir uma verdadeira ferramenta de aprendizagem, contribuindo para um maior índice de sucesso do sistema educativo português, parece-nos fundamental, por um lado, o desenvolvimento de estudos que evidenciem as atividades e os processos de elaboração e expressão do conhecimento, no quadro de diferentes disciplinas escolares, e o papel que a escrita neles pode desempenhar; por outro, importaria levar a cabo um conjunto de mudanças a diferentes níveis: escola, sala de aula, materiais pedagógicos.

No nível da escola, será importante uma aposta na transversalidade, envolvendo tanto os professores de língua materna como os professores das outras disciplinas. Seria ainda desejável uma verdadeira aposta em áreas curriculares que, em nossa opinião, não têm sido devidamente aproveitadas: o estudo acompanhado e, sobretudo, a área de projeto, ou a realização de projetos, de um modo geral, que poderiam constituir espaços privilegiados para o desenvolvimento de competências de aprendizagem.

No nível da sala de aula, importaria um trabalho que concretizasse, nas práticas pedagógicas, o princípio da transversalidade aqui referido. No caso dos professores de língua portuguesa, a quem, enquanto especialistas, cabe a promoção das competências verbais implicadas na aquisição e expressão do conhecimento, seria importante uma aposta em dimensões previstas nos textos oficiais, como, por exemplo, a leitura para informação e estudo, a escrita não compositiva, a escrita para a aquisição de técnicas e modelos, trabalhando sobre conteúdos e textos do âmbito de outras disciplinas. Aos docentes de outras áreas pede-se-lhes que, tomando consciência da importância da escrita na aprendizagem, programem tarefas que a impliquem, tendo em vista a construção do conhecimento.

Finalmente, no nível dos materiais pedagógicos, mais que manuais e cadernos de atividades que favoreçam a mera reprodução de um conhecimento já formatado no momento em que é transmitido, seria interessante encontrarmos produtos que, pela natureza das tarefas neles propostas, pudessem ajudar os alunos a aprender e a aprender a aprender.

Assumindo-se a escrita como competência transversal e sabendo-se que ela desempenha um papel crucial não só na disciplina de língua materna (funcionando como meio e objeto de aprendizagem), mas também nas restantes disciplinas como ferramenta de aprendizagem, a capacidade de escrever é um inegável fator de sucesso escolar, por estar ao serviço da aprendizagem e por constituir um mecanismo valioso na concretização de formas diversas de comunicação de saberes.

\section{REFERÊNCIAS}

Applebee, Arthur. Writing and reasoning. Review of Educational Research, Washington: The Association, v. 54, n. 4, p. 577-596, 1984.

Armbruster, Bonnie; Mc Carthey, Sarah; Cummins, Sunday. Writing to learn in elementary classrooms. In: Indrisano, Roselmina; Paratore, Jeanne. Learning to write, writing to learn - theory and research in practice. Newark: IRA, 2005. p. 71-96. 
Barbeiro, Luís. Escrita: construir a aprendizagem. Braga: IEP/UM, 2003.

Bereiter, Carl; Scardamalia, Marlene. The psychology of written composition. Hillsdale, New Jersey: Lawrence Erlbaum Associates, 1987.

Camps, Anna. Pontos de vista sobre o ensino-aprendizagem da escrita. In: Carvalho, José; Barbeiro, Luís; Silva, António; Pimenta, Jorge. A escrita na escola, hoje: problemas e desafios. Braga: CIEd/UM, 2005. p. 11-26.

Carvalho, José; Barbeiro, Luís; Pimenta, Jorge. La escritura, elaboración y expresión del conocimiento: la escritura como instrumento de aprendizaje. In: BARrio; José. El proceso de enseñar lenguas: investigaciones en didáctica de la lengua. Madrid: La Muralla, 2008. p. 57-88.

Castro, Rui. Para a análise do discurso pedagógico. Constituição e transmissão da gramática escolar. Braga: CEEP/UM, 1995.

Choppin, Alain. Manuels scolaires: histoire et actualité. Paris: Hachette, 1992.

Crinon, Jacques. Des élèves tiennent le journal de leurs apprentissages. Cabiers Pédagogiques, Paris: CRAP, n. 388-389, p. 62, 2000.

Emig, Janet. Writing as a model of learning. College Composition and Communication, Urbana: NCTE, v. 28, n. 2, p. 122-128, 1977.

Flower, Linda; Hayes, John. A cognitive process theory of writing. College Composition and Communication, Urbana: NCTE, v. 32, n. 4, p. 365-387, 1981.

Fonseca, Fernanda. Gramática e pragmática. Estudos de linguística geral e de linguística aplicada ao ensino do português. Porto: Porto Editora, 1994.

Grabe, William; Kaplan, Robert. Theory and practice of writing. London: Longman, 1996.

Hand, Brian; Prain, Vaughan. Teachers implementing writing-to-learn strategies in junior secondary science: a case study. Science Education, Hoboken: Wiley-Blackwell, v. 86, n. 6, p. 737-755, 2002.

Jewitt, Carey. Technology, literacy and learning: a multimodal approach. London: Routledge, 2006.

KLEIN, Perry. Reopening inquiry into cognitive processes in writing-to-learn. Educational Psychology Review, New York: Springer, v. 11, n. 3, p. 203-270, 1999.

Martlew, Margaret. Problems and difficulties: communicative aspects of writing development. In: The psychology of written language. Developmental and educational perspectives. Chichester: John Wiley \& Sons, 1983. p. 295-333.

Olson, David. Conceptualizing the written word. An intellectual autobiography. Written Communication, Thousand Oaks: Sage Publications, v. 12, n. 3, p. 277-297, 1995.

Pereira, Sónia. Efeitos da sequência didáctica em textos escritos no $1^{\circ}$ ciclo do ensino básicoo relato. 2007. Dissertação (Mestrado em Línguas no $1^{\circ}$ ciclo do ensino básico) Universidade de Aveiro, Aveiro, 2007. 
Portugal. Ministério da Educação. Currículo Nacional do Ensino Básico-competências essenciais. Lisboa: Ministério da Educação, 2001.

Ramos, João. Escrita, construção e expressão do conhecimento - uma análise de práticas no âmbito de diferentes disciplinas. 2006. Dissertação (Mestrado em Educação) Universidade do Minho, Braga, 2006.

Rivard, Léonard. A review of writing-to-learn in science: implications for practice and research. Journal of Research in Science Teaching, Hoboken: Wiley-Blackwell/National Association for Research in Science Teaching, v. 31, n. 9, p. 969-983, 1994.

Sim-Sim, Inês; Duarte, Inês; Ferraz, Maria José. A lingua materna na educação básica. Lisboa: ME, 1997.

Tynjälä, Päivi; Mason, Lucia; Lonka, Kirsti. Writing as a learning tool: an introduction. In: . Writing as a learning tool. Integrating theory and practice. Dordrecht, Netherlands: Kluwer Academic Press, 2001. p. 7-22.

Vygotsky, Lev S. Pensamento e linguagem. Lisboa: Antídoto, 1979.

MANUAIS DE ESTUDO DO MEIO ( $\left.1^{\circ} \mathrm{CICLO}\right)$

M1 - Dinis, Conceição; Ferreira, Luís. Caminhos - $3^{\circ}$ ano. Porto: Porto Editora, 2005. M2 - Rodrigues, Angelina; Pereira, Cláudia; Borges, Isabel; Azevedo, Luísa. Estudo do meio - 3. Porto: Areal Editores, s.d.

M3 - Castro, Maria José; Gomes, Fernando; Costa, Maria Teresa. Trampolim-estudo do meio - 3. Porto: Porto Editora, 2005.

M4 - Monteiro, João; Paiva, Miguel. Estudo do meio do João - 3o ano. Gaia: Gailivro, 2005.

M5 - Freitas, Maria; Letra, Carlos. Saltitão - estudo do meio - 3o ano. Gaia: Gailivro, 2005.

M6 - Rocha, Alberta; Lago, Carla do; Linhares, Manuel. Amiguinhos - estudo do meio e expressões - $3^{\circ}$ ano. Lisboa: Texto Editores, 2005.

M7 - Pinto, Ana; Carneiro, Maria Aurélia. Bambi 3 - estudo do meio. Porto: Porto Editora, 2005.

M8 - Silva, Conceição; Monteiro, Maria Lurdes. Júnior - estudo do meio - $3^{\circ}$ ano. Lisboa: Texto Editores, 2005.

\section{MANUAIS DE CIÊNCIAS FÍSICO-QUÍMICAS ( $\left.3^{\circ} \mathrm{CICLO}\right)$}

M1 - Rodrigues, Maria Margarida; Dias, Fernando. Ciências na nossa vida: Terra no espaço/Terra em transformação. Porto: Porto Editora, 2005.

M2 - Cavaleiro, Maria Neli; Beleza, Maria Domingas. FQ: Terra no espaço/Terra em transformação. Porto: Edições Asa, 2005.

M3 - Figueiredo, Teresa. Eureka! CFQ - Terra no espaço/Terra em transformação. Lisboa: Texto Editora, 2002. 


\section{MANUAIS DE CIÊNCIAS DA NATUREZA ( $\left.3^{\circ} \mathrm{CICLO}\right)$}

M1 - Silva, Amparo; Santos, Maria Ermelinda; Mesquita, Almira; Baldaia, Ludovina; FÉlix, José. Planeta vivo. Porto: Porto Editora, 2003.

M2 - Мотta, Lucinda; Viana, Maria Anjos. Bioterra: Terra no espaço/Terra em transformação. Porto: Porto Editora, 2005.

M3 - Lima, Jorge; Portugal, Isabel; Santos, Lurdes. Vita: Terra no espaço/Terra em transformação. Porto: Edições Asa, 2005.

MANUAIS DE GEOGRAFIA ( $\left.3^{\circ} \mathrm{CICLO}\right)$

M1 - Gomes, Ana; Вото, Anabela. Fazer geografia. Porto: Porto Editora, 2005.

M2 - Ribeiro, Isabel; Costa, Madalena; Carrapa, Maria Eduarda. Contrastes. Porto: Areal Editores, 2004.

M3 - Matos, Maria João; Castelẽo, Rui. Geografia: espaços. Carnaxide: Constância Editores, 2002.

MANUAIS DE HISTÓRIA ( $3^{\circ}$ CICLO)

M1 - Alves, Eliseu; Maia, Rui; Cunha, Eugénia; Ferrão, Maria. História 7. Porto: Porto Editora, 2003.

M2 - Oliveira, Ana; Cantanhede, Francisco; Torrão, Paula; Catarino, Isabel. História 8. Lisboa: Texto Editores, 2003.

M3 - Neves, Pedro Almiro; Maia, Cristina; Baptista, Dalila; Amaral, Cláudia. Novo Clube de história 8. Porto: Porto Editora, 2004.

\section{SOBRE OS AUTORES}

José António Brandão Carvalho é doutor em educação pela Universidade do Minho. Professor da mesma instituição.

E-mail: jabrandao@ie.uminho.pt

Luís Filipe Barbeiro é doutor em educação pela Universidade do Minho. Professor do Instituto Politécnico de Leiria (IPL). E-mail: barbeiro@ipleiria.pt

Recebido em maio de 2011

Aprovado em maio de 2011 


\section{JOSÉ ANTÓNIO BRANDÃO CARVALHO E LUÍS FILIPE BARBEIRO}

\section{Reproduzir ou construir conhecimento? Funções da escrita no contexto escolar português}

A escrita pode ser perspetivada como ferramenta de aprendizagem, desempenhando um papel relevante nos processos de aquisição, elaboração e expressão do conhecimento. O papel da escrita na construção do conhecimento pode ser compreendido focando as características linguísticas, os processos cognitivos implicados, ou a prática social e cultural em que se insere. Tendo por base o relevo que, no contexto da escola, a escrita pode assumir nesses processos, realizamos um 
estudo com o objetivo de verificar até que ponto essa dimensão é valorizada na escola portuguesa no ensino básico. Optamos por dois percursos metodológicos complementares: a análise de manuais escolares e um inquérito a professores por meio de questionário. Os dados recolhidos demonstram que, no contexto escolar, o uso da escrita acontece, sobretudo, no quadro de tarefas que visam à reprodução de informação e que, só muito raramente, ela é perspetivada como promotora da elaboração do conhecimento.

Palavras-chave: escrita; ferramenta de aprendizagem; reprodução/construção de conhecimento.

\section{Knowledge reproduction vs. knowledge construction? Uses of writing in Portuguese schools}

Writing may be considered a learning tool, playing a relevant role in knowledge acquisition, development and expression. The role of writing in knowledge construction can be understood focusing on linguistic features, the cognitive processes involved, or the social and cultural practice in which it occurs. Based on the relevance that writing can take in these processes in the school context, we conducted a study aimed at verifying the extent to which this dimension is valued in Portuguese schools of primary education (1st to 9 th grades). We chose two complementary methodological pathways: analyzing textbooks and inquiring teachers by means of a questionnaire. The data collected show that, in the school context, writing is used particularly in tasks aimed at the reproduction of information and that only very seldom is writing viewed as a promoter of knowledge creation.

Keywords: writing; learning tool; knowledge reproduction/construction.

\section{¿Reproducir o desarrollar conocimiento? Las funciones de la escritura en el contexto escolar portugués}

La escritura se puede entender como un instrumento de aprendizaje en la medida que desempeña un papel importante en los procesos de adquisición, elaboración y expresión de conocimiento. El papel de la escritura en la construcción del conocimiento se puede comprender considerando centrales las características lingüisticas, los procesos cognitivos implicados, o la práctica sociocultural en la que se insiere. Teniendo por base la importancia que la escritura como herramienta de aprendizaje puede tener en el contexto escolar, se llevó a cabo un estudio con el fin de averiguar hasta quépunto esa dimensión se valora en la escuela portuguesa de educación básica. Hemos optado por dos caminos metodológicos complementarios: el análisis de libros de texto y de las respuestas al cuestionario propuesto a los profesores. Los datos han demostrado que, en el contexto escolar, el uso de la escritura se da, en la mayoría de los casos, en el cuadro de tareas que tienen como objetivo la reproducción de conocimiento y que, rara vez, se ve como una herramienta que promueve la elaboración del conocimiento.

Palabras clave: escritura; herramienta de aprendizaje; reproducción/construcción del conocimiento. 